\title{
Reducing Appointment Lead-Time in an Outpatient Department of Gynecology and Obstetrics Through Discrete-Event Simulation: A Case Study
}

Ortiz Barrios, Miguel Angel; McClean, S. I. ; Nugent, Chris D.; Castillo Zea, Anyeliz Yulieth

\begin{abstract}
Appointment lead-time is a critical variable in outpatient clinic services. In Gynecology and Obstetrics departments, longer appointment lead times are associated with lower patient satisfaction, the use of more complex healthcare services, development of long-term and severe complications and the increase of fetal, infant and maternal mortality rates. This paper aims to define and evaluate improvement alternatives through the use of Discrete-event simulation (DES). First, input data analysis is performed. Second, the simulation model is created; then, performance metrics are calculated and analyzed. Finally, improvement scenarios are designed and assessed. A case study of a mixed-patient type environment (Perinatology and Gynecobstetrics) in an outpatient department has been explored to verify the effectiveness of the proposed approach. Statistical analysis evidence that appointment lead times could be significantly reduced in both Perinatology and Gynecobstetrics appointments based on the proposed approaches in this paper.
\end{abstract}

\section{Keywords}

Appointment lead-time, Discrete event simulation, Gynecology, Healthcare, Obstetrics, Outpatient department 